\title{
Os estudos de mídia e a problemática epistemológica da teoria da midiatização - uma nova escolástica?
}

\section{Francisco Rüdiger}

Doutor; Pontifícia Universidade Católica do Rio Grande do Sul e Universidade Federal do Rio Grande do Sul

frudiger@ig.com.br

\section{Resumo}

Nosso objetivo consiste, primeiro, em reconstituir os antecedentes históricos de onde emergiu e os estágios reflexivos em que se desenvolveu a problemática teórica da midiatização de que tantos estudiosos da comunicação passaram a falar no curso do último decênio. Em segundo, tratase de mostrar como, neste período, foi ela elaborada em termos metodológicos, para embasar a proposição de um programa de pesquisa supostamente capaz de conferir uma disciplina ou constituir um paradigma nesta área do conhecimento. Enfim, procede-se à crítica de suas realizações e doutrina, levantando a hipótese de que, com isso, se está diante de uma nova escolástica.

\section{Palavras-chave}

Midiatização. Teorias da comunicação.

\section{Introdução}

Midiatização se tornou, no curso dos últimos anos, termo emergente com que, entre muitos acadêmicos, se pretende relatar o processo pelo qual, nos tempos modernos, ao menos, a comunicação e a vida social são impactadas pela presença massiva e o extraordinário desenvolvimento de instituições tecnológicas como a imprensa, o rádio, a televisão e a internet. Durante bom período, os estudos de mídia, isto é, dos fenômenos associados a estas instituições, partiram da premissa de que elas todas eram uma influência pontual sobre a sociedade e que tarefa daqueles estudos consistiria em analisá-la. Agora, proclamam os partidários da nova teoria, precisamos nos mover para outro patamar. As circunstâncias no 
obrigam a adotar uma nova perspectiva, de acordo com a qual está tudo midiatizado. As instituições puramente sociais perderam a relativa independência que teriam possuído até passado recente diante do avanço da mídia, na medida em que os processos desta última passaram a intervir e transformar seus vários setores de tal modo que elas, as instituições, não têm mais como serem pensadas e se moverem fora das circunstâncias que a mídia e os meios lhes impõem (LUNDBY, 2014; KROTZ, 2007; FAUSTO NETO, 2008; SODRÉ, 2002).

Que os aparatos e meios técnicos de comunicação se constituam em uma instituição e intervenham de modo sistêmico na formação e desenvolvimento da vida social moderna foi entrevisto originalmente por Schaffle e Small, no final do século XIX (HARDT, 1979, p. 41-74 e 187-202). Observado genericamente em seu impacto nas relações sociais pelos luminares da Escola de Chicago (CZITROM, 1982, p. 91-121), relatado desde o ponto de vista de seus acentos tecnológicos pela Escola de Toronto (WATSON; BLONDHEIM, 2007). Enfim, teorizado em conjunto como processo de reestruturação formal da sociedade, cultura, comunicação e subjetividade mais recentemente por autores como Thompson (1995).

As comunicações de e em massa, ao constituírem-se em um sistema ou tornarem-se instituição rotineira, transformam as formas de experiência e os padrões de interação legados pela tradição, redesenhando os limites entre o público e o privado, o segredo e a publicidade, sem abolir os antigos. A experiência se amplia e repercute na própria maneira como se desenvolve o sujeito, estimulando, pela dispersão, a percepção do eu, na medida em que os bens culturais, a começar pela palavra, passam a ter uma circulação, acessibilidade e impacto virtualmente global e democrático.

Visualizando no termo midiatização a senha para resumir o processo históricosociológico assim assentado, os teóricos e estudiosos que dele lançam mão visam ir além. Desejam explorá-lo como recurso metodológico para desenvolver um programa de pesquisa empírica em que o foco reside na descoberta do modo como as comunicações, mediando a prática, ajudam a moldar os vários campos da atividade social. A pesquisa empírica e etnográfica anterior procurava sabê-lo pontualmente, fosse com a noção de efeitos, fosse com o exame isolado da recepção das mensagens originadas da mídia. A perspectiva em juízo almeja superá-la, partindo da premissa de que a mídia, em vez de meramente impactar em, se encontra agora enraizada institucionalmente dentro de todas as searas sociais, sem deixar de possuir sua própria força e identidade.

Apesar de bastante difundido a esta altura, o estatuto epistemológico e o próprio sentido teórico da expressão designadora deste viés ainda são, contudo, incertos, variando seu 
entendimento e acento na reflexão teórica e prática de pesquisa, conforme se passa de um para outro de seus usuários. Quer-se com o termo midiatização referir a uma perspectiva de estudo emergente, por esclarecer de modo mais sólido; a um programa de pesquisa; a um expediente heurístico; a uma teoria social da mídia. ou a tudo isso junto? Para uns, vislumbra-se nele a possibilidade de, enfim, definir um conceito central e, com tanto, o objeto dos estudos de mídia, embora predominem os que nele vejam apenas mais um aporte para a teoria social. Há quem veja na midiatização um processo meta-histórico, visto que desde a origem, a humanidade fez uso de meios para interagir, enquanto outros restringem a validade do termo à modernidade avançada, quando eles supostamente passariam a ter sua própria lógica. 0 problema no encaminhamento do assunto reside no fato de que seu próprio conceito ainda não está normalizado (BASTOS, 2012).

Simplificando, verifica-se que, partindo da análise da literatura especializada, há pelo menos duas formas de entendê-lo. A primeira segue os princípios do construcionismo sociológico, vendo na midiatização o termo com que se pode dar conta de um fator possuidor de sua própria lógica e que se impôs à constituição e funcionamentos das muitas esferas da vida social na contemporaneidade. A segunda se pauta por critérios empiristas, entendendoa como referência conceitual de um expediente metodológico com que se pode guiar a pesquisa sobre o modo como os sujeitos presentes nestas esferas acolhem os meios e com eles agenciam as circunstâncias mais próprias destas esferas.

Ambas veem nos processos e meios de comunicação midiada uma força possuidora de crescente influência em todos os setores da vida social que não se reduz à transmissão de mensagens, e na midiatização termo com que se pode relatar tudo isso, superando os esquemas em termos de estímulo e resposta ou causa e efeito que, no passado, tentaram explicar o poder da mídia na sociedade. 0 conteúdo ou ideologia veiculado por ela é menos relevante do que os formatos que a estruturam, os meios não são recursos de sujeitos que os instrumentalizam à distância. A mídia constitui uma força que pervade todos os campos sociais, na medida em que os sujeitos e instituições não têm mais como não adotá-la e, assim, não se converterem em sujeitos e instituições midiáticas.

Quer numa, quer noutra, retoma-se a hipótese da mídia forte perante as outras ordens de ação social, na medida em que se parte da premissa de que os sujeitos destas últimas se encontram agora em situações nas quais passaram a depender dos meios, para poder agir socialmente. Apenas varia o modo de entendê-la, sendo para uns a chave terminológica de uma teoria, de acordo com a qual a mídia estaria impondo uma nova lógica à ação social; 
enquanto outros a veem como senha designadora de um programa de pesquisa de cunho empírico, cujo propósito é descobrir como os meios são agenciados em distintos contextos societários (cf. a discussão mais recente em AMPUJA et al, 2014; DEACON, STANYER, 2014; HEPP et al, 2015).

Nosso objetivo, neste trabalho, consiste primeiro em reconstituir os estágios reflexivos de formação desta problemática, chamando atenção para seu cunho essencialmente fenomenológico. No momento seguinte, trata-se de mostrar como, em anos recentes, foi ela retomada em termos metodológicos, para embasar a formulação dos programas de pesquisa acima notados. Enfim, procede-se à crítica de suas teses, levantando a suspeita de que, com tanto, se está diante da proposição de uma nova escolástica.

\section{Antecedentes}

Ainda em estágio de aprimoramento conceitual e ordenamento metodológico, a teoria da midiatização se encontra pré-figurada em meio à área de estudos de mídia e cultura desde, pelo menos, a década de 1970. Ernst Manheim, sabe-se, empregou o termo para, nos anos 1930, dar conta da classe de mediação que transformou o debate privado e o discurso deliberativo em fenômeno público agenciado por meio da imprensa (MANHEIM [1933] 1936; cf. HABERMAS, [1962] 1984; AVERBECK, 2014, p. 119-123). Pondo de lado esta referência pioneira e passando a focar no significado mais atual, isto é, na sua associação com um poder que possuiriam os meios de comunicação, menção originária sem dúvida se encontra no ponto em que se entrecruzam as obras de Jean Baudrillard e Jean Franklin.

Disse o primeiro que, em nosso tempo, a mídia, de figura marginal, se tornou instituição, que enseja uma "mass-midiatização", salientando, no entanto, que esta não se refere “[...] a um conjunto de técnicas de difusão de mensagens, mas à imposição de modelos [...]", pois “[...] o que é midiatizado não é o que passa pela imprensa, pela televisão , pelo rádio: é o que é assumido pela forma/signo, articulado em modelos, regido pelo [que o autor chama de] código" (BAUDRILLARD, [1972] 1988, p. 224-225). 0 segundo detalhou o assunto. 0 poder se constitui em forma social da qual o discurso é aspecto estrutural que passa, historicamente, por três estágios: o verbo, o retórico e o cibernético, aos quais corresponderiam três expressões: o mito, a ideologia e a midiatização. A última pode nos levar a pensar no surgimento de um processo puramente técnico e instrumental, mas seria errôneo vê-la deste modo. 
A midiatização não designa apenas a ação mesma dos mass media enquanto meios de difusão, mas antes o esquema de sentido, de linguagem, de relações sociais e de 'comunicação' que, remetendo àqueles meios, extravasa seu marco ao se impor como estrutura e modelo universalizado [de exercício do poder]. (FRANKLIN, 1975, p. 293).

Chegada a modernidade avançada, a racionalidade semiológica aos poucos vai assumindo a condição de mediação que cancela todas as outras e, absorvendo as contradições reais do mundo histórico, tende, com apoio nos meios técnicos de informação, a anulá-las, criando uma "comunicabilidade universal, uma comunhão planetária" (p. 387). Destarte, midiatização significa o processo estrutural de imposição tecnológica de um sistema em que o concreto se torna abstrato sob a forma de discurso e imagem para serem consumidos, se não a criação de um novo cosmos, marcado pela hiper-realidade (BAUDRILLARD, 1976).

Nos Estados Unidos, a perspectiva assim esboçada foi, em vez disso, vislumbrada e desenvolvida em chave essencialmente midiocêntrica por Altheide e Snow (1979; 1985). Segundo os autores, os aparatos de comunicação em massa criaram, com o tempo, uma lógica que, primeiro penetra em todas as áreas da vida para, em seguida, impor-lhes os parâmetros com que seus sujeitos veem e conhecem a realidade. No passado, houve quem os pensasse e, mesmo, tentasse usá-los como instrumentos para induzir os outros à ação, mas não é nesta base que convém entender o poder da mídia. Existe agora uma situação em que ela, tendo desenvolvido seus próprios formatos e protocolos, dita o modo como as pessoas se relacionam com sua época (1979, p. 10).

A forma como a mídia importa está na difusão de uma lógica através da qual a experiência coletiva é colonizada pelos formatos que a mídia mesma criou, os eventos e ações sociais passam a ser estruturados de acordo com as regras que, por ela ditadas, lhes organizam a percepção. 0 poderio da mídia se origina do fato de sua presença e pervasão tornarem toda a vida social instituição midiática, considerando o enquadramento da realidade ao nosso alcance. A vida coletiva se deixou saturar por um processo através do qual a mídia não apenas nos impôs sua maneira de ver e pensar a realidade, mas teria se tornado tornado a instituição dominante na sociedade.

Para Altheide e Snow, as formas sociais são estruturadas epistemicamente pelas matrizes da mídia (1985, p. 13-14). Guy Debord havia se cingido a falar da espetacularização. Para aqueles primeiros, há que estudar outras, como o fluxo contínuo e regular de mensagens, a expressão anônima, coletiva e impessoal, a projeção valorativa de tudo o que filtram, etc. As pessoas, salientam, não são forçadas a adotar os formatos que estruturam suas ope- 
rações e conteúdos porque os responsáveis pela midiatização assim o desejaram, mas para não perderem contato com o que está acontecendo e desfrutarem de benefícios. 0 resultado é o surgimento de um gigantesco filtro ou enquadramento, cuja lógica ou modo de ser, as estratégias discursivas e os esquemas formais, vistos de maneira óbvia ou naturalista pelos sujeitos sociais, definem o ritmo e os acentos, os princípios de simbolização e critérios de ordenamento da experiência coletiva.

Os autores observam, é certo, que a mídia não dita nada à sociedade, antes interage com ela, salientando, contudo, que "nesta interação, a forma que lhe é própria acaba sendo aceita como a perspectiva através da qual os vários problemas institucionais são interpretados e resolvidos" (1979, p. 15). O fato é que a realidade social passou a ser constituída, codividida e reproduzida de acordo com os formatos por ela criados para ordenar, expor e veicular coletivamente esta experiência, não fazendo diferença se seu cunho é ou não interativo, a ponto de ser com base neles que ela está passando a ser transformada (p. 11).

Depois, Adriano Rodrigues $(1988 ; 1990)$ retomou e ampliou este ponto de vista, falando em campo da mídia para relatar a maneira como a comunicação humana se converte em uma esfera relativamente autônoma e especializada com o desenvolvimento da modernidade. A ruptura da tradição e do comunitarismo, combinada com o desencadear do individualismo, institui um registro dominado pela ideia de mediação entre as várias esferas que daquela ruptura emergem. 0 campo da mídia surge na medida em que o conjunto dos meios de comunicação, visto como instituições ao mesmo tempo técnicas e sociais, se converte em palco da mediação que lhes contêm o movimento centrífugo, assegura-lhes a comunicação e, por fim, mantêm discursivamente no horizonte a figura da sociedade.

Destarte, pode-se entender por tanto um conjunto de instituições indispensável

[...] ao funcionamento de uma sociedade dividida e confrontada com a necessidade de assegurar, apesar de tudo, uma relativa homogeneidade da sua estrutura e um entendimento acerca dos seus princípios, objetivos, prioridades e modalidades de ação. (RODRIGUES, 1990, p. 153).

O acento, vê-se, é funcionalista. 0 campo da mídia, crê o autor, é um espaço em que se procura compor valores legítimos, mas divergentes; agenciar os objetivos e interesses presentes nas "[...] instituições que adquiriram nas sociedades modernas o direito de mobilizarem autonomamente o espaço público." (RODRIGUES, 1990, p. 152).

O exercício desta função, no entanto, supõe e exige a relativa autonomia deste campo, sob pena de ele vir a ser tragado por uma ou outra esfera ou instituição. A prova de que ele a possui residiria no desenvolvimento de protocolos, rotinas e rituais próprios, conforme se 
pode constatar analisando o formato e periodicidade dos telejornais ou das peças de publicidade, as convenções que estruturam sua recepção, etc.; mas também os princípios estratégicos de comunicação que lhe são subjacentes, como o pluralismo e liberdade de expressão, o emprego da fala persuasiva e o direito à privacidade nas sociedades democráticas (RODRIGUES, 1990, p. 159-160).

0 autor reconhece que os demais campos também criam e mantêm seus próprios serviços de comunicação com o público e com a mídia: conferências de imprensa, ações de relações públicas, campanhas de publicidade e propaganda, etc.; que há um jogo dialético entre eles e o campo da mídia, no qual se trava uma disputa entre controle e transparência dos dados, sigilo e informação.

A natureza vicária do campo dos media tem a ver com a delegação por parte dos outros campos de uma parte das suas funções expressivas, daquelas que dizem respeito à inscrição da sua ordem no espaço público, da componente exotérica das respectivas funções expressivas. (RODRIGUES, 1990, p. 156).

A nota é relevante para lembrar o caráter relativo da autonomia possuída pelo campo da mídia e, assim, da midiatização que através dele se agencia, mas não deve nos fazer esquecer que esta relativização não lhe tira a autonomia, revelada toda a vez em que não apenas os protocolos, rotinas e rituais, como sublinha o autor, mas os interesses gerados nas instituições em que se inscrevem se desatrelam de compromissos externos e, ainda que em situação de mercado, passam a se pautar apenas pela procura, esclarecimento e publicidade de informações, por exemplo, como acrescenta Pross (1970).

\section{Doutrina}

Querem o que de novo ou diferente estes que, nos últimos anos, retomam com o termo midiatização esta linha de reflexão? A julgar pelo que dizem, o principal seria sua aplicação à análise concreta da maneira como os meios de comunicação penetram, articulam e influenciam os demais campos sociais (LUNDBY, 2014). A ênfase, agora, estaria na pesquisa. A expressão serviria para estruturar uma agenda de investigação que, partindo da premissa da mídia forte, objetiva reavaliar empírica ou etnograficamente as questões concernentes à sua presença e influência na cultura e na sociedade.

O conceito de culturas da mídia como culturas da midiatização [que propomos] não pretende ser uma teoria acabada, mas antes um convite ao desenvolvimento de uma teorização empiricamente fundada a respeito da 
maneira pela qual nossas culturas estão mudando com o avanço da midiatização. (HEPP, 2012, p. 142).

O pressuposto, procedamos a um detalhamento, é o de que podemos entender por midiatização o processo através do qual os vários setores da atividade social passam não só a ser influenciados pela mídia mas se tornam, eles mesmos, agências que colaboram em seu movimento de expansão, conforme escancararia, neste momento, o fenômeno das redes sociais. Os aparatos de comunicação passaram a ter um modus operandi institucional que lhe permite não apenas estarem presentes em todos os campos da atividade humana, mas colocar esta última na sua dependência, como teriam antevisto os pioneiros, ao falar em lógica midiática ou campo da mídia.

Segundo Muniz Sodré, por exemplo, podemos entender por midiatização um construto conceitual com que se procura dar conta do processo que permeia as relações que entretemos uns com os outros por meios da mídia e que, fomentando seus padrões e formatos, constitui uma forma de vida autônoma.

A sociedade contemporânea rege-se pela midiatização, quer dizer, pela tendência à virtualização ou telerrealização das relações humanas, presente na articulação do múltiplo funcionamento institucional e de determinadas pautas individuais de conduta com as tecnologias de comunicação. (SODRÉ, 2002, p. 21).

Para este autor, há que distinguir entre midiatização e mediação, da qual aquela seria apenas uma forma, essencialmente econômica e tecnológica. A mediação diz respeito às instituições ou formas reguladoras do relacionamento em sociedade, à concretização do que vincula os seres humanos.

Já a midiatização é uma ordem de mediações socialmente realizadas no sentido da comunicação entendida como processo informacional, a reboque de organizações empresariais e com ênfase num tipo particular de interação - a que poderíamos chamar de 'tecnointeração', caracterizado por uma espécie de prótese tecnológica e mercadológica da realidade sensível, denominada médium. (SODRÉ, 2002, p. 21).

Para outros, o conceito pode ser explorado de forma um pouco mais prosaica.

Define-se midiatização como o processo pelo qual a cultura e sociedade se tornam cada vez mais dependentes da mídia e sua lógica, um processo que se caracteriza dualmente pelo fato de a mídia adquirir o status de uma instituição semi-independente e ao mesmo tempo se integrar na estrutura da vida social de outras instituições sociais e esferas culturais. (HJARVARD, 2013, p. 153).

A sociedade moderna se encontra submetida à lógica da mídia, na medida em que, amparada em uma autonomia que teria lhe dado o mercado, esta última não só adquiriu 
relativa autonomia mas, tendo colonizado todos os demais campos sociais, passa a estruturar suas práticas pelo viés da comunicação. Os meios se encaixaram nos vários campos sociais e em suas circunstâncias eles, em múltiplas direções, agora intervêm e influem de modo aparentemente inapelável. A cultura passou a ser instância dependente da mídia, visto a mídia não apenas ter se tornando uma instituição que não apenas impõe seu próprio ritmo e lógica mas, espalhando-se por todos os cantos, se integrou às operações cotidianas de todas as demais.

\begin{abstract}
'Lógica midiática' não significa que há uma racionalidade universal, linear ou única por trás de todos os meios de comunicação. 0 termo deve ser entendido como abreviatura conceitual para os vários 'modi operandi' institucionais, estéticos e tecnológicos da mídia, incluindo os modos pelos quais ela distribui recursos materiais e simbólicos, operando com a ajuda de regras formais e informais. (HJARVARD, 2013, p. 17).
\end{abstract}

No passado, foram os meios empregados pontualmente como tais, recursos ou instrumentos com os quais se transmitiam mensagens com os mais variados objetivos; posteriormente, passou-se a organizá-los, para atenderem os interesses de outras instituições; agora eles passaram a constituir uma instituição de direito próprio que, impulsionada por fatores econômicos e pela disseminação de seus equipamentos, se encontra presente nas práticas de comunicação de virtualmente todos os setores sociais (SCHULZ, 2004). A sociedade está sendo midiatizada, na medida em que suas várias atividades passaram a depender de meios técnicos que, ao mesmo tempo, lhe determinam e influem no desenvolvimento. As ações sociais não apenas passaram, em boa medida, a se estruturar e ocorrer com o auxílio dos dispositivos eletrônicos e digitais de comunicação, mas, com isso, estão assumindo novas dinâmicas e contornos, para além dos efeitos imediatos e pontuais que aqueles meios podem desencadear.

Se, por um lado, a midiatização afeta/ interfere em diferentes práticas sociais, tem, ao mesmo tempo, sua existência e suas lógicas reconhecidas por outros campos sociais, que dela se servem como 'mediação', ou ainda, como 'condição de produção' de suas ações comunicativas [...] estabelecendo uma nova ambiência em que os processos midiáticos, suas linguagens e suas práticas, além de serem novos operadores de inteligibilidades, organizam o funcionamento das novas práticas dos campos sociais, bem como suas próprias discursividades. (FAUSTO NETO, 2006, p. 54).

Desde o ponto de vista da história das ideias, observemos, as proposições assim elaboradas consistem em um subcapítulo tardio da chamada teoria da modernização, surgida após a II Guerra Mundial. Sucessora das filosofias da história surgidas no século XVIII, postu- 
la a mesma que as sociedades se modernizam na medida em que, reagindo ao tradicionalismo, ingressam em um processo de transformação permanente. Impulsiona-o aparecimento e conjugação de uma série de fatores institucionais, geradora de uma dinâmica interna e de uma nova forma de relacionamento com as demais sociedades, através das quais as pessoas, embora inicialmente resistam, passam a se engajar naquela transformação.

Que a teoria da midiatização se situe no horizonte desta problemática prova-o a lembrança, feita por muitos de seus porta-vozes, de que não é ela um fator isolado. A midiatização é apenas uma parte ou aspecto de um conjunto mais abrangente. Formam-no processos outros, como a industrialização, a urbanização, a secularização, a individualização, a mercantilização, a globalização, etc. A midiatização se mistura e colabora com eles para desvincular as relações sociais dos contextos imediatos e reinscrevê-las mediatamente em âmbitos de cunho tecnológico e globalizado (GIDDENS, 1991).

Thompson abordara a problema do poder pelo viés da ideologia, salientando os fundamentos organizacionais que, em tese, lhe potenciam o alcance, mas fala que o fenômeno precisa ser analisado em relação aos contextos específicos em que são produzidos e apropriados pelos sujeitos sociais (THOMPSON, [1989] 1995, p. 345). Os proponentes da teoria da midiatização seguem e aprofundam este raciocínio, observando que sua influência todavia não é linear, visto que o fato das instituições sociais se tornarem dependentes da presença dos meios para manterem suas rotinas sempre comporta uma margem de negociação. A submissão à lógica da mídia não exclui sua acomodação às circunstâncias locais, suas adaptação aos interesses específicos de cada contexto, a passagem por mediações, levando alguns a inclusive preconizar o abandono da referência à lógica em seu tratamento.

Para Lundby, Couldry e outros advogados do conceito cabe, com efeito, impugnar o entendimento do termo como imposição de uma única e mesma lógica, originária da mídia mesma, a todas as esfera da sociedade. Para eles e outros, esta visão o torna vulnerável. Os meios obedecem a vários ritmos e distintos modos de funcionamento. Em linhas gerais, “[...] é muito difícil ver uma única lógica que explicaria todo o espectro de efeitos que os teóricos [institucionalistas] da midiatização reclamam." (COULDRY, 2012, p. 136). De fato, a sociedade não se deixa midiatizar por uma só lógica, não há uma única lógica permeando todos os campos midiatizados. A lógica, se há, se desenvolve regionalmente, no processo de difusão e circulação dos meios (LUNDBY, 2009, p. 116).

A pesquisa não pode apresentar como dado o que deve, antes, ser descoberto: é necessário especificar como os vários meios, em cada caso, impactam na interação social, para 
tirar da midiatização sua aparência de movimento monolítico, linear e determinista. Os processos de midiatização não impactam sempre da mesma maneira. As formas sociais reagem e se desenvolvem a cada vez de um modo próprio ao seu avanço (COULDRY, 2014).

Destarte, Andreas Hepp (2012) defende que midiatização seria vista melhor como um construto histórico-sociológico, ou panorama, com o qual se procura relatar um metaprocesso que, supostamente subjacente, precisa ser examinado em detalhe e sem preconceitos, empiricamente. A mídia não tem lógica porque, em cada caso, a midiatização ocorre de forma distinta. A cultura se deixa colonizar pelo processo em condições que ela, a mídia, não esgota e, por isso, aquela cultura não pode ser vista como uma só coisa, como cultura de massa, por exemplo. A sociedade se estrutura cada vez mais midialmente, mas seu resultado não é linear e monolítico, visto o processo passar por mediações locais em meios as quais a mídia é cultivada de distintas maneiras, que devem ser pesquisadas em sua interação e diversidade (p. 29).

A pretensão de reconhecer características essenciais à midiatização incide em erro: estamos aqui diante uma referência de cunho metodológico, e não de uma teoria, por mais que se reconheça que a presença dos meios tenha um efeito modelador, estruturante. 0 efeito da midiatização precisa ser examinado a partir da interação dos usuários com os meios. A midiatização não obedece a uma lógica que teria a ver com os meios, porque "[...] somos nós, os seres humanos, que agimos comunicativamente em relação aos meios [...]" (Hepp, 2012, p. 46). 0 processo deve ser descrito localmente, ainda que, em função dele, estes locais sejam globalizados, porque só neste âmbito é que ele se efetiva, valendo mais, talvez, falar em culturas da mídia do que em midiatização.

Jesus Martín-Barbero (1987) e Roger Silverstone ([1999] 2002), o primeiro sobretudo, haviam preconizado e apoiado a tese de que a mídia precisa ser estudada localmente, em suas mediações políticas, religiosas, familiares, etc. 0 foco da análise não está nos meios mas na sua integração em processos diversos e contextos específicos, onde interagem com outros fatores (cf. AVERBECK, 2011). Hepp se deixa, em parte, influenciar pelas ideias de ambos, argumentando que a midiatização, isto é, a crescente presença da mídia em todos os setores sociais, precisa ser cultivada de baixo para cima a fim de se efetivar.

Avalia-se os processos de midiatização no plano dos processos de transformação em andamento e conforme eles, a cada vez modo particular e distinto, se associam uma variedade de mediações específicas através dos meios de comunicação. (HEPP, 2012, p. 38). 
O poder que não falta aos meios, sua capacidade de reestruturar os ambientes sociais, varia de contexto para contexto - trabalho, casa, igreja, lazer - e se desenvolve, a cada vez, de maneira distinta, ensejando o surgimento de culturas midiatizadas, em vez de uma cultura dominada pela mídia, como tende a nos fazer pensar uma visão holística e essencialmente institucional do processo.

\section{Problematização}

Origina-se da época de Kant uma distinção entre saber empírico e transcendental (reflexivo) que se desdobra, depois de Hegel, em uma consciência historicizada do primado gnosiológico do segundo sobre o primeiro, conforme se vê, em chave materialista, nos escritos de Marx. Gadamer ([1960] 1977) disso tomou ciência, para tirar a conclusão epistemológica de que, nas ciências da cultura, ao menos, o conhecimento se estrutura previamente a toda e qualquer análise pela transmissão histórica da linguagem com que a desenvolvemos.

De Cooley a McLuhan foram vários os que, de maneira objetivista, chamaram atenção para a forma como os meios de comunicação impactaram nas estruturas da experiência do homem moderno. Os teóricos da midiatização deram um passo adiante, ao notar que, convertendo-se em instituição, eles redimensionam a comunicação, passando a reestruturar nossa maneira de ver a realidade e interagir socialmente. 0 ponto que tem lhes escapado à reflexão é o quanto sua própria perspectiva a respeito da mídia e sua conexão com o restante da vida social tem sido colonizada por esta situação.

Friedrich Krotz chegou a notar que, embora se misturem e se integrem, "no mundo capitalista" os vários aspectos formadores do processo de modernização "dependem da dimensão econômica” e, por isso, "[...] a comercialização é o processo básico a fornecer estímulo ao conjunto de suas ações", incluindo a "midiatização [...]" (KROTZ, 2007, p. 259). Apesar disso, verifica-se que, em se tratando dos trabalhos a respeito desta última, a tendência é isolar este fator, proceder à sua exploração analítica, com relativa indiferença pela influência dos demais aspectos citados nos fenômenos em que ele intervém.

Hjarvard o comprova da maneira mais simplória o possível observando que,

[...] sim, a mídia vende produtos aos consumidores, mas também prestam serviço a suas audiências e usuários, na condição de público em geral tanto quanto de indivíduos pertencentes a um contexto institucional em particular. (2013, p. 25). 
A hipótese de que este serviço também esteja mercantilizado nem de longe lhe passa pela cabeça. Aparentemente, a preocupação abstrata em, senão provar a relevância do processo, pelo menos focar a todo custo no que tem a ver com a mídia, que asseguraria a identidade institucional da pesquisa, não apenas bloqueia a exploração multicausal da situação em exame, mas impõe uma aparência de determinação da mesma pela midiatização.

A percepção por seus teóricos elaborada de que o conhecimento não é mais mediado apenas pela linguagem, mas pela linguagem sujeita e desenvolvida por aparatos de comunicação que se tornaram instituições - eles ainda não viram - contaminou-lhes acriticamente o próprio pensamento, na medida em que este tem se revelado incapaz de relativizar esta mediação.

Para eles, recapitulemos, a comunicação midiada instala, com o tempo, uma nova ordem, ao revolucionar a experiência sensível. Superamos a época em que nos informávamos com os jornais, levávamos em conta o que dizia o rádio, por exemplo. A mídia se tornou instituição, cujas rotinas estão incorporadas em praticamente todas as nossas atividades, nos vários setores da vida. A representação da realidade passou a depender de uma lógica midiática, que procede a uma espécie de filtragem de suas circunstâncias. Os formatos com que os aparatos e meios de comunicação enquadram ou agenciam a realidade, seja ou não mediada e adaptada localmente, nos impõem uma maneira de vê-la da qual nos tornamos prisioneiros sem saber, visto se naturalizar na consciência do público.

Que isso seja visto como um poder que passou a imperar sobre nós se aceita, fora inclusive notado previamente, por gente como Lippmann ([1922] 2008), Adorno ([1963] 1969) e Ellul (1962), entre outros. Ocorre que este escândalo não é menor que o fato de sermos todos escravos da língua que falamos, como mal ou bem nos lembrou Roland Barthes. "Falar não é comunicar, como se repete com demasiada frequência, é sujeitar-se", escreveu ele, visto que "na língua reside um poder", este que me obriga a dizer apenas o que ela permite (BARTHES, [1977] 1980, p. 12-15)

A midiatização tem atraído muito pesquisadores porque se afigura como conceito com que se almeja dispor de um princípio de integralização dos estudos da midia e que pode ajudar a disciplinar este campo de estudos. 0 problema, reza sua teoria, não é o conteúdo que suas mensagens veiculam, mas a presença e o formato que, independentemente daquele primeiro, as telas dos aparatos midiáticos impõem ao curso da vida social em sua variedade de manifestações. A gramática que os meios empregam para revelar a realidade e a necessidade que deles temos para agir socialmente em um mundo globalizado contam mais que as 
intenções com que se elabora o conteúdo, contribuindo para estruturar e definir a situação em que estamos metidos, sem que disso, em geral, nos apercebamos.

Referir-se a um poder comunicacional (CASTELLS, 2009), enquanto capacidade desenvolvida midiaticamente de, por exemplo, estocar e acessar informações onde se esteja e quando se deseje, coordenar ações à distância ou se expressar para uma audiência potencialmente universal, vale como lembrança, mas é pouco mais que um truísmo, visto que esta capacidade está contida analiticamente no desenvolvimento do próprio conceito de meio de comunicação. Nesse sentido, o poder da mídia, exceto pela relevância e alcance, não é distinto do poder das redes de energia elétrica e abastecimento d'água sobre a vida humana: constitui um recurso objetivo, cujo cunho, ainda que não seja neutro, pois se agencia desigualmente, é, depois de instalado, trans-social, pré-determinado.

0 ponto que, passando da fenomenologia mais geral para a reflexão teórica mais específica, interessa é, por isso, saber que condições lhe determinam concretamente e que sentido sua exploração mais típica e constante, nestas condições, lhe confere. 0 verdadeiro problema para quem deseja refletir histórica e sociologicamente sobre a mídia, objetive ou não desenvolver um programa de investigação, não reside no poder da mídia, sempre mais ou menos dado; mas no modo como ela estrutura e agencia material e tecnologicamente relações sociais de poder em meio às quais ela é explorada estrategicamente de modo mais ou menos típico ou extraordinário (cf. GIDDENS, [1984] 1989; FOUCAULT, [1977] 1981).

No passado, o rádio e a televisão serviram para legitimar tanto regimes de direita quanto de esquerda, cuja fortuna, contudo, não dependeu essencialmente da sua influência sobre os aparatos de comunicação, nem muito menos de um poder que estes últimos lhes transfeririam em bloco e mecanicamente. Que as redes sociais tenham introduzido uma nova variável nos movimentos sociais, redimensionando suas táticas e estratégias de ação, não se discute. No entanto, cabe lembrar que, elas, por outro lado, não estão blindadas ao uso e exploração por seus adversários. 0 fenômeno tem colaborado para reestruturar o cenário político contemporâneo, trazendo-lhe, por exemplo, mais instabilidade, mas não tem um sentido único ou intrínseco do ponto de vista dos agentes que com ela se engajam (MOROZOV, 2011; 2013).

Em termos metodológicos, os aparatos de comunicação e cultura, no estudo de caso ou monografia, precisam ser vistos como mediações de processos cujo sentido não é em si mesmo comunicacional, entendendo-se por mediação a manifestação reflexiva de um movimento histórico mais abrangente e determinante, "que assume a aparência de imediatici- 
dade apenas porque e na medida em que, por um lado, falta a consciência da mediação e, por outro lado, [suas circunstâncias] foram, por isso, arrancadas ao complexo das suas determinações reais e colocadas em um isolamento artificial (LUKÁCS, [1923] 1974).

\section{Análise}

Será possível ir além deste tipo de generalidades? Os proponentes da teoria da midiatização acreditam que sim. Os resultados de seus esforços, contudo, não nos parecem animadores. 0 programa de pesquisa objetiva saber como a mídia veio a influenciar a sociedade das mais variadas formas, ao se integrar e passar a interagir em outras esferas sociais, mas aparentemente a pesquisa mesma não tem conseguido ir além, em suas conclusões, da reiteração de truísmos e banalidades.

A admissão que o conceito não designa uma única lógica, operando de modo genérico, mas uma multiplicidade delas, operando em planos específicos, renovou-lhe a perspectiva epistemológica. A relevância que ele pode ter na pesquisa, esclareceu-se, depende da nossa capacidade de estudar empiricamente a forma como a penetração dos meios na vida social se mistura e combina com outras forças e fatores, em vez de postular-lhe abstratamente (KROTZ; HEPP, 2014).

De que modo julgar, se não com o rótulo de trivialidades, porém, as constatações daí resultantes de que os educadores precisam lidar com uma clientela midiatizada antes de entrar na escola, a religião se tornou um fenômeno midiático, as famílias usam os meios para se orientar em suas atividades cotidianas, os partidos políticos os empregam para se comunicar com os segmentos que lhes interessam, as pessoas passaram a cuidar mais da própria imagem conforme vão sendo objeto de monitoramente fotográfico, as crianças incorporaram às suas brincadeiras utensílios que relativizam o papel dos pais, e as empresas que os produzem se tornam dependentes da ficção criada para consumo infantil?

Os teoremas amarrados com o termo midiatização, à primeira vista, impressionam, sugerindo que, enfim, as pesquisas sobre cultura e meios de comunicação encontraram um conceito capaz de lhes fornecer unidade teórica e fundamento metodológico. A reflexão a respeito da sua aplicação na pesquisa revela, no entanto, que se sucumbe ao ridículo de fornecer da vida social o retrato em geral simplório e anedótico que boa parte da mídia lhe elabora.

Argumenta-se simploriamente, por exemplo, que, no passado, a relação entre os políticos e os meios era de exploração dos últimos pelos primeiros. A opinião pública era manu- 
faturada pela imprensa. Agora, segue a tese, a formação da opinião pública se tornou comparativamente mais livre. As agências e meios de comunicação que a elaboram e difundem se regem pela competição em uma espécie de mercado de ideias. Destarte,

Os atores e instituições políticas estão se tornando cada vez mais influenciadas pelo modus operandi da mídia, de modo que podemos considerar a midiatização da política como uma mudança da balança do poder entre as duas instituições, a política e a mídia, em favor da última. (HJARVARD, 2013, p. 77).

Que os atores políticos tenham passado a depender da sua habilidade em comunicar estrategicamente com e através da mídia, ou que esta, às vezes, revele o poder de lhes desmascarar os crimes e excessos, entretanto, não significa que o jogo do poder seja decidido nesta arena (OAKES, 1992; MARCHETTI, 2008). Que as práticas religiosas convirjam e, em muitos casos, se fundam com as práticas midiáticas, visto que a atividades da primeira passaram a se articular com a forma como sua mensagem passou a ser formatada e veiculada pela mídia (MARTINO, 2012; 2014), não significa que a fé que as mobiliza, para serem religiosas, se origine e se explique via midiatização (MORGAN, 2011).

Silverstone (2002, p. 33) lembrara o óbvio ao observar que "todos nós somos mediadores" e que, para estudar as mediações, precisamos, portanto, ir além do "ponto de contato entre os textos midiáticos e seus leitores ou espectadores" - sem se dar conta que, baseandose unicamente neste princípio e focando o raciocínio na mídia, priva-se a pesquisa de uma referência conceitual capaz de lhe impedir a queda no truísmo hiper-empirista de acordo com o qual, por princípio, tudo conta, visto que tudo conecta com o resto.

A proposta de se estudar o assunto via o conceito de midiatização representa, nesse sentido, um corretivo metodológico salutar, ao sugerir-lhe parâmetros para a pesquisa mas, por outro lado, peca pelo seu midiocentrismo, visto manter em mente as premissas escolásticas de que a cultura precisa ser sempre explicada em referência aos meios de comunicação e de que esta midiatização é sempre relevante em suas manifestações. 0 foco da pesquisa segue sendo protocolar, senão burocrático-normativo, já que sua tarefa é sempre "[...] relatar a crescente influencia da comunicação em determinadas tecnologias [que pervadem o cotidiano]." (HEPP, 2012, p. 29).

As culturas que interessam, embora variadas e diferentemente, sempre se estruturam pela presença dos meios de comunicação. A comunicação existente entre seus participantes é o que mais importa, na medida em que é o que está midiatizado. As comunicações “[...] só se tornam influentes [no cotidiano] ao interagirem na prática: este processo não é causal, 
nem dado de forma autônoma, ocorrendo através da formatação das ações [por aquelas culturas promovida]." (HEPP, 2012, p. 60).

O peso e relevância desta formatação, para não falar das circunstâncias que presidem à sua criação, contudo, jamais são postos em questão. A cultura, embora plural, é sempre "cultura da mídia", ambiente cujos fatores e recursos formadores de sentido são, ainda que de forma distinta, sempre doutrinariamente pensados em relação à crescente onipresença dos meios técnicos de comunicação (cf. SLATER, 2013).

As comunicações têm impacto na maneira como construímos nosso conhecimento da realidade em interação dialética como outros fatores, mas isso pode nos levar a descoberta de que, às vezes ou em muitos casos, aquela construção depende muito mais destes do que delas: pode haver sua presença, mas a influência é, em última análise, trivial, relevante unicamente no discurso que a toma como referência (ideológica). A possibilidade de que a midiatização, assim entendida, seja mediadora de processos cujas fontes e sentido não promanam dela mesma raramente é entrevista, na medida em que se trabalha com a premissa de que, para seus teóricos, é sempre ela a principal mediação da cultura, da comunicação e da sociedade.

O fato de o noticiário das emissoras ser um produto posto em um mercado e isso condicionar a seleção e relato do que passa pelo mundo é, para os teóricos da midiatização, menos relevante do que o fato das noticias serem formatas pela televisão. 0 golpe de Estado, a crise política que lhe deu origem e o banho de sangue dos que a ele se opuseram não importam tanto pelo que podem significar de restrição à liberdade de expressão, mas pelo modo como foram publicizados. A pesquisa empírica pode ser tão irrelevante quanto a doutrinação teórica - prova disso é, para nós, a perspectiva da midiatização.

Nos relatos de pesquisa estruturados com a abordagem que pudemos compulsar, jamais se pergunta se a mídia é relevante no contexto social em análise, de que modo, se há, suas variáveis e eventuais problemas têm ligação significativa com a mídia. A premissa é a de que, por estar presente, esta é relevante e precisa ser determinada, mesmo a custo de banalidades, como a de que os homens revelam maior soberania nos manejo nos equipamentos de comunicação doméstica do que as mulheres e, em análise conclusiva, “[...] o lar midiatizado represente um local de referência para a concretização múltipla de um processo de midiatização abrangente." (PEILL; RÖSER, 2014, p. 246).

Apesar de eventualmente se afirmar que a midiatização constitui eixo conceitual de uma teorização interdisciplinar que deve ser testada e avaliada empiricamente, para não se 
tornar matéria de crença e repetição estereotipada, a pesquisa que objetivou pô-la à prova no campo político, saber se a ação política é guiada por suas próprias metas, ou pela intervenção da mídia não conseguiu ir além da conclusão puramente formal de que a conexão entre uma e outra possui duas mãos, é contingente e varia de país para país (ESSER, 2014, p. 8).

Aplicando-o assim, Esser não logra ver que conceito de midiatização tem a ver com uma reflexão fenomenológica de cunho histórico-sociológico de pouca relevância na pesquisa, na medida em que estará sempre presente onde houver institucionalização de meios e mídia. 0 afastamento da procura de efeito e a premissa de que há intenções que ela recomenda não autorizam pensar que nos disponibiliza um novo programa de pesquisa. A esta altura, um programa de pesquisa significativo seria mostrar onde ela, a mídia, não impacta, encontra resistência, ou interage de maneira negativa, como dão exemplo os estudos de Bogosh e Peleg sobre a midiatização dos processos judiciais (BOGOSH; PELEG, 2014) ou o de Janson sobre os limites do uso do celular entre os imigrantes africanos na Europa (JANSON, 2009).

A premissa das pesquisas sobre midiatização “[...] é a que não há nenhuma parte da sociedade contemporânea que não seja afetada pela mídia e que, por isso, está se tornando cada vez mais difícil distinguir entre a mídia e outras partes da sociedade [...]" - mas os autores mesmo notam que demonstrá-lo é outra questão. "A natureza, extensão e efeitos da influência midiática são sempre contextuais e situacionais.", precisa ser pesquisado empiricamente (ESSER, 2014, p. 10) mas, como dito, não tem sido, em nosso ver, muito mais que trivial o que tem mostrado os resultados deste trabalho.

Fausto Neto (2008) emprega a pesquisa para sustentar que o campo político está tomando como sua competência o emprego e desenvolvimento de práticas midiáticas, antes restritas ao campo jornalístico. Para ele também, os acontecimentos passaram a ser tecidos no contexto de uma midiatização generalizada, que penetra ou atravessa a política e a religião, mas do qual estas, ao mesmo tempo,apropriam-se e exploram. Surgiu com a institucionalização da mídia uma lógica que não se restringe mais apenas às empresas especializadas no ramo, ao funcionar por vários campos sociais, como procura exemplificar sua análise das operações enunciativas e estratégias de divulgação do mal que acometeu o ex-presidente, empregadas pelo Instituto Lula, em 2008 (FAUSTO NETO 2008).

A pesquisa se distingue do modelo dominante, ao trabalhar a problemática da midiatização desde um ângulo essencialmente semiótico. A estratégia consiste em recorrer à cui- 
dadosa análise do discurso e dos modos de enunciação que aquele órgão levou a cabo em sua página da internet e, assim, aparentemente agendou a cobertura por parte da imprensa e a atenção dada ao fato pela opinião pública, para arguir que "[...] uma das características da midiatização é a de enfraquecer a atividade tecno-simbólica da mediação midiática profissional [...]", porque "[...] dela roubaria o ato de ofertar sentidos, em primeira mão, sobre a enfermidade do ex-presidente [...]" (FAUSTO NETO, 2008, p. 310).

O problema consiste em nosso ver no cunho artificioso de todo o procedimento, todavia muito bem cuidado, como é marca nos texto do autor, já que o estudo de caso não tem serventia outra que ilustrar um raciocínio que, por um lado, se sustentaria sem necessidade da inovação terminológica que estamos analisando e, de outro, poderia muito bem se encaixar em outras formas de reflexão teórica. 0 caso, em suma, não é relativizado, não se nota, por exemplo, que, no passado, as práticas de relações públicas, publicando house-organs e fotografias e/ou fazendo lobby, por exemplo, já recorriam ao expediente estudado no texto. 0 relato em foco chama muito mais atenção para a retórica e o método de estudo da midiatização do que para o conhecimento que deles pode resultar, visto que a problemática de fundo poderia, por exemplo, ser arranjada com os conceitos de relações públicas e propaganda político-institucional.

O principal, contudo, é que a relevância do caso mesmo não é discutida, restringida que fica a análise à ilustração de uma problemática cujo alcance, já arguimos, é muito limitado ou pouco significativo na prática de pesquisa, exceto para o treinamento de profissionais de mídia. 0 artigo mal toca no que o comunicado que virou notícia tem de específico e representa social e historicamente, limitando-se a especular com a hipótese da "celebração da doença em comunidade" que ela agenciaria como parte de uma suposta estratégia do presidente e, “[...] talvez, alguma associação com a biografia 'comunitária' de Lula.” (FAUSTO NETO, 2008, p. 319).

A sociedade e cultura contemporâneas se tornaram dependentes dos meios de comunicação em tal grau que não se pode mais considerá-los de modo isolado e separado, passando por alto sua apropriação e emprego cotidianos, o modo como eles intervêm em todas as áreas e ajudam a construir a realidade para seus sujeitos - mas será que sua presença sempre importa em impacto significativo e, quando se verifica mudança numa área em que ela impacta, a razão é a mídia, conforme sugere a proposição da teoria?

As convicções que impedem os partidários da teoria em foco de levar em conta estes problemas estão na essência de sua projeção como ideologia, de seu agenciamento como 
motivo de crença, que os cega para o fato de que, embora a midiatização tenha se tornado uma dimensão irredutível de todos os processos sociais, isso não a torna mais importante do que, por exemplo, a eletrificação, possuidora de igual condição, e nem de longe tem o alcance do principal derivado desta última, que é a informatização (HUGHES, 1983; MINC, NORA [1977] 1984).

Os teóricos do agenda-setting dos meios de comunicação afirmam seu poder de pauta em relação à consciência pública, sem se questionar quem e o que agenda a atividade das agências de comunicação e se o pretendido agendamento, às vezes, não tem qualquer relevância nos acontecimentos. Os partidários do conceito de midiatização parecem convencidos de que os meios têm um papel na transformação da cultura e da sociedade, cabendo a pesquisa demonstrá-lo, mas será sempre assim e, no caso de haver, será sempre relevante ou merecedor de exposição?

Conviria pensar que a midiatização não apenas está sujeita a influências e mudanças que, em tese, lhe podem ser contrárias mas, ainda que presente, pode ser um fator causalmente irrelevante, em comparação com outros, no que está em jogo em uma situação sob análise. 0 significado concreto não apenas precisa ser decidido caso a caso, mas deve ser buscado sem a convicção doutrinária de que está sempre presente, tem força e, por isso, será relatado com proveito para o conhecimento. A presença e influência da mídia não só assumem formas variadas e distintas, mas podem ser insignificantes, se é que importam como tal, mídia, seja para o sujeito social, seja para o estudioso da cultura e da sociedade.

Os proponentes da teoria da midiatização se empertigam ao usar o termo, sem perceber as limitações de seu alcance e propriedade, visto que, a esta altura, não há mais nada que, de uma ou de outra forma, escape à influência ou processamento pelos meios de comunicação, a exemplo do que se pode falar em referência ao termo globalização. 0 conceito surgiu sem crítica e se ajustou às demandas por autonomia que faz um campo acadêmico de estatuto epistemológico subalterno, convertendo-se em eixo de uma ideologia, segundo a qual a mídia passou a ser o centro da mudança social, não importa o quanto outros possam falar em dinheiro e informatização, por exemplo. 0 resultado é a propagação da crença, ensejada pelo próprio processo, de que seu motor é a tecnologia, seu comando está nas mãos de seus usuários e sua influência desconhece limites, à revelia do que possam dizer os que estudam política, economia e história. 


\section{Considerações finais}

Hoje se aceita que todas as instituições são também instituições de mídia, na medida em que não apenas elas mas, via internet, os indivíduos mesmos que as agenciam se tornaram, virtualmente todos, sujeitos midiáticos ativos e engajados (CASTELLS, 2009). Que isso tenha impacto na formação da experiência do homem moderno e na dinâmica de suas várias relações não o é menos - mas, para além disso, não há especificamente mais para afirmar do que o já resumido, em linhas gerais, por John Thompson (1995).

Assim sendo, julgamos que as tentativas de converter a teoria da midiatização em fundamento de um programa de pesquisa tendem a transformar a expressão em um termo retórico, aplicado em trabalhos de conclusões declaratórias, nos quais as análises se resumem a postular a midiatização de alguma coisa, senão de tudo, porque embora inefável, o processo é inevitável e a tudo abarca.

A mídia se tornou um fator ou uma influência na construção social da realidade e em suas representações, mas isso não quer dizer que faltem outras e que ela seja a mais relevante - exceto se a tomarmos como tópico de um projeto que, no essencial, já a determinou e, na pesquisa, tem se revelado, em nosso ver, incapaz de gerar resultados relevantes, devido ao aprisionamento em um conceito de pouco alcance epistêmico e hermenêutico.

Os aparatos e sistemas tecnológicos de comunicação, sim, se converteram em uma realidade objetiva que está presente virtualmente em todos os campos da práxis e cujo emprego se torna agora, com a mídia digital portátil e interativa, potencialmente acessível a todos os indivíduos, em todo lugar e a qualquer momento, desde tenra idade. 0 fato de a vida social ser cada vez mais mediada pelos processos e formatos em parte definidos pelos meios técnicos revela um poder da mídia cuja origem e efeitos todavia não têm como ser determinados investigando-se apenas ela mesma, sobretudo se o interesse for desenvolver a pesquisa social e histórica em sentido especializado (MILLS, [1959] 1961).

Ainda que o inserido em uma empreitada de corte epistemológico, Muniz Sodré nos fornece claro exemplo de que, mantendo em vista suas motivações originárias, pode-se trabalhar teoricamente de maneira crítica e reflexiva com o conceito de midiatização (SODRÉ, 2014, p. 154-188). A tendência vigente, contudo, não nos parece ser esta. A atmosfera de suspeita e denúncia que, apesar do viés mistificador, pairava nas primeiras menções à lógica midiática desapareceu. A reflexividade não se desenvolveu criticamente, antes passou a fomentar um discurso de forte acento ideológico, em cujo âmago se encontra o desejo inútil de legitimar uma instituição que se sustenta muita bem sem este suplemento. 
Projetado além do que lhe cabe dar conta por boa parte de seus entusiastas, vê-se assim que o termo midiatização se converteu em eixo discursivo de uma atividade escolástica, na qual se notam os sinais de um credo positivista na ciência pela ciência que, incentivando a pesquisa sem referência à razão prática, trivializa os resultados que esta pesquisa pode produzir, nivela axiologicamente sua relevância e burocratiza nossa vontade de saber.

\section{Referências}

ADORNO, Theodor. Prólogo a la televisión. In: ADORNO, Theodor. Intervenciones. Caracas: Monte Avila, [1963] 1969. p. 63-74

ALTHEIDE, David. Media power. Beverly Hills: Sage, 1985.

ALTHEIDE, David; SNOW, Robert. Media logics. Beverly Hills: Sage, 1979.

AMPUJA, M. et al. E. String and weak forms of mediatization theory. Nordicom Review, Gothenburg, n. 35, p. 111-123, 2014.

AVERBECK, Stefanie. Understanding mediatizatin in "first modernity". In: LUNDBY, Knut (Org.). Mediatization of communication. Berlin: Walter de Gruyter, 2014.

AVERBECK, Stefanie. French and Latin American perspectives on mediation and mediatization. Empedocles, Bristol, v. 3, n.2, p. 177-195, 2011.

BARBERO, Jesus. De los medios a las mediaciones. Barcelona: Gustavo Gilli, 1987.

BARTHES, Roland. Aula. São Paulo: Cultrix, [1977] 1980.

BASTOS, Marco. Medium, media, mediação e midiatização. In: MATTOS, M. A. et al. (Org.) Mediação \& midiatização. Salvador: Edufba, 2012.

BAUDRILLARD, Jean. Crítica à economia política do signo. Lisboa: Edições 70, [1972] 1988.

BAUDRILLARD, Jean. L'exchange symbolique et la mort. Paris: Gallimard, 1976.

BOGOCH, Bryna; PELEG, Anat. Law in the age of media logic. In: LUNDBY, Knut (Org.).

Mediatization of communication. Berlin: Walter de Gruyter, 2014.

CASTELLS, Manuel. Comunicación y poder. Madri: Alianza, 2009.

COULDRY, Nick. Media, society, world. Cambridge: Polity, 2012.

COULDRY, Nick. When mediatization hits the ground. In: KROTZ, F.; HEPP, A. (Org.).

Mediatized worlds. Londres: Macmillam, 2014. 
CZITROM, Daniel. Media and the american mind. Chappel Hill: University of North Carolina, 1982.

DEACON, David; STANYER, James. Mediatization: key concept of concept bandwagon. Media, Culture, and Society, New York, v. 36, n. 7, p. 1032-1044, 2014.

ELLUL, Jacques. Propagandes. Paris: Armand Collin, 1962.

ESSER, Frank; STRÖMBAC, Jesper (Org.). Mediatization of politics. Londres: Palgrave, 2014.

FAUSTO NETO, Antonio. Fragmentos de uma analítica da midiatização. Matrizes, São Paulo, v.2, p. 89- 105, 2008.

FAUSTO NETO, Antonio. Será que ele é? Onde estamos? A midiatização de um discurso proibido. Ícone, Recife, v. 1, p. 39-57, 2006.

FOUCAULT, Michel. Poderes y estrategias. In: FOUCAULT, Michel. Dialogo sobre el poder. Madri: Alianza, 1981.

FRANKLIN, Jean. Le discours du pouvoir. Paris: UGE, 1975.

GADAMER, Hans-Georg. Verdad y método. Salamanca: Siguemé, [1960] 1977.

GIDDENS, Anthony. As consequências da modernidade. São Paulo: Unesp, 1991.

GIDDENS, Anthony. A constituição da sociedade. São Paulo: Martins Fontes, [1984] 1989.

HABERMAS, Jürgen. Mudança estrutural da esfera pública. Rio de Janeiro: Tempo Brasileiro, [1962] 1984.

HARDT, Hanno. Social theories of the press. Beverly Hills: Sage, 1979.

HEPP, Andreas. Cultures of mediatization. Oxford: Blackwell, 2012.

HEPP, Andreas et al. Mediatization: theorizing the interplay between media, culture e society. Media, Culture, and Society, New York, v. 37, n. 2, p. 314-322, 2015.

HUGHES, Thomas. Networks of power. Baltimore: Johns Hopkins University, 1983

HJARVARD, Stig. The mediatization of culture and society. Londres: Routledge, 2013.

JANSON, André. Mobile belongings. In: LUNDBY, Knut (Org). Mediatization: concept, changes, consequences. Nova York: Lang, 2009.

KROTZ, Friedrich. Mediatisierung von Kommunication. Wiesbaden: VS, 2007.

KROTZ, Friedrich; HEPP, Andreas (Org.). Mediatized worlds. Londres: Macmillam, 2014.

LIPPMANN, Walter. Opinião pública. Petrópolis: Vozes, [1922] 2008. 
LUKÁCS, György. História e consciência de classe. Porto: Escorpião, [1923] 1974.

LUNDBY, Knut (Org.). Mediatization of communication. Berlin: Walter de Gruyter, 2014.

LUNDBY, Knut (Org). Mediatization: concept, changes, consequences. Nova York: Lang, 2009.

MANHEIM, Ernst. La opinión pública. Madri: Editorial Revista de Derecho Privado, 1936.

MARCHETTI, Dominique (Org.). Communication et mediatisation de l'état. Grenoble: Pug, 2008.

MARTINO, Luis. A midiatização da religião e esfera pública nas eleições paulistas de 2012.

Revista Brasileira de Ciência Política, Brasília, v. 14, p. 7-26, 2014.

MARTINO, Luis. Mediação e midiatização da religião em suas articulações teóricas e práticas. In: MATTOS, Maria Ângela; JANOTTI JUNIOR, Jeder; JACKS, Nilda (Org.) Mediação \& midiatização. Salvador: Edufba, 2012.

MINC, A.; NORA, S. A informatização da sociedade. Lisboa: Europa-América, [1977] 1984.

MILLS, Wright. La imaginación sociológica. Mexico: FCE, [1959] 1961.

MORGAN, David. Mediation or mediatization. Culture and Religion, v. 12, p. 137-152, 2011.

MOROZOV, Evgeny. The net-delusion. Nova York: Public Affairs, 2011.

MOROZOV, Evgeny. To save everything, click here. Nova York: Public Affairs, 2013.

OAKES, Guy. Image and reality in Media Worlds. International Journal of Politics, Culture, and Society, New York, v. 5, n. 3, p. 439-463, 1992.

PEILL, C.; RÖSER, J. The meaning of home in the context of digitalization, mobilization and mediatization. In: KROTZ, F. ; HEPP, A. (Org). Mediatized worlds. Londres: Macmilam, 2014.

PROSS, Harry. Publizistik. Neuwied: Luchterhand, 1970.

RODRIGUES, Adriano. Estratégias da comunicação. Lisboa: Presença, 1990.

RODRIGUES, Adriano. 0 campo dos media. Lisboa: Vega, 1988.

SCHULZ, Winfried. Reconstructing mediatization as analitycal concept. European Journal of Communication, Braga, v. 19, n.1, p. 87-101, 2004.

SILVERSTONE, Roger. Por que estudar a mídia. São Paulo: Loyola, [1999] 2002.

SLATER, Dan. New media, developments and globalisation. Cambridge: Polity, 2013. 
SODRÉ, Muniz. A ciência do comum. Petrópolis: Vozes, 2014.

SODRÉ, Muniz. Antropológica do espelho. Petrópolis: Vozes, 2002.

THOMPSON, John. The media and modernity. Oxford: Polity, 1995.

THOMPSON, John. Ideologia e cultura moderna. Petrópolis: Vozes [1989] 1995.

WATSON, Rita; BLONDHEIM, Menahem. The Toronto School of Communication Theory. Toronto: University of Toronto, 2007.

\title{
Media studies and the epistemological problematics of mediatization theory: a new scholasticism?
}

\begin{abstract}
Our aim here is, at first, to reconstruct the historical background from which has emerged and the reflective stages in which has developed the theoretical problematics of mediatization about which many scholars of communication studies have began to speak since last decade. After this, the article intends to show how this concept has been elaborated as a methodology during this period, to support the proposition of a research program supposedly capable to confer a discipline or to be a paradigm in this area of knowledge. Finally, we proceed to the criticism of its accomplishments and doctrine, raising the hypothesis that with all of this we are facing the specter of a new scholasticism.
\end{abstract}

\section{Keywords}

Mediatization. Communication theories.

Recebido em 31/08/2015

Aceito em 15/12/2015 